\title{
The conduct of successful multi-site EU collaborative research: the EPSILON Study
}

\author{
GRAHAM THORNICROFT, THOMAS BECKER, MARTIN KNAPP, \\ HELLE CHARLOTTE KNUDSEN, AART SCHENE, MICHELE TANSELLA, \\ JOSÉ LUIS VAZQUEZ-BARQUERO, THE EPSILON STUDY GROUP
}

\section{BACKGROUND}

The EPSILON (European Psychiatric Services: Inputs Linked to Outcome Domains and Needs) study was an EU-funded Concerted Action Programme, funded between 1996-1999 by EU BIOMED-II (Becker et al., 1999). The authors of this paper were the Principal Investigators (PIs) with the exception of Dr. Becker, who joined the study team at an early stage of the work as the Scientific Coordinator. The aims of the study are set out in Becker $e t$ al. (2000). Briefly it was a study whose overall objectives were to (1) produce instrument translation, adaptation and reliability assessment of five key mental health service research scales in 5 European languages, and also to conduct (2) a comparative, cross-sectional study of care for representative people with schizophrenia in these five countries. Six research teams in five centres were involved, and the teams are located in Amsterdam, Copenhagen, London (Centre for the Economics of Mental Health and Section of Community Psychiatry, Institute of Psychiatry), Santander and Verona. Centres had experience in health services research and instrument development, and all had access to mental health services providing care for local catchment areas. The scales are intended at this stage to be primarily used in research settings.

The instruments used assess a variety of dimensions of the care process, such as needs for care, service utilisation and costs, informal carer involvement, quality

\footnotetext{
Indirizzo per la corrispondenza: Professor G. Thornicroft, Section of Community Psychiatry (PRiSM), Health Service Research Department, Institute of Psychiatry, Kings College London, De Crespigny Park, London SE5 8AF, United Kingdom.

Fax: +44-207-277.1462

E-mail: g.thomicroft@iop.kcl.ac.uk
}

of life and service satisfaction. This research instrumentation was used to study care for people with schizophrenia in five centres cross-sectionally in a sample of patients in contact with secondary mental health services. More specifically, the EPSILON study aims: (1) to produce standardised versions of five key research instruments in five languages, (2) to compare data about social and clinical variables, mental health care and costs, and (3) to test instrument-specific and cross-instrument hypotheses.

Five key study instruments (more details are given elsewhere including in Becker et al., 2000; Chisholm et al., 2000; Gaite et al., 2000; Knudsen et al., 2000; McCrone et al., 2000) were adapted for use in the five languages and different service settings:

- Camberwell Assessment of Need (CAN; adapted CAN$\mathrm{EU})$

- Client Service Receipt Inventory (CSRI; adapted CSSRI-EU)

- Involvement Evaluation Questionnaire (IEQ; adapted IEQ-EU)

- Lancashire Quality of Life Profile (LQoLP; adapted LQoLP-EU)

- Verona Service Satisfaction Scale (VSSS; adapted VSSS-EU).

\section{PREPARATION OF THE GRANT APPLICATION}

The study partners involved had already a track-record of collaboration through their involvement in establishing of the European Network for Mental Health Service Research (ENMESH) in 1992. There was already, therefore, before the writing of the application for funding, a good degree of mutual knowledge, understanding and trust between the Principal Investigators, which 
each led for one of the instruments used in the EPSILON study. This led to a clear area for each site in which they could expect scientific output and publication credit. This became important at a later stage when genuine differences of opinion emerged in the design and conduct of the study, because these differences could be discussed and debated in a constructive way. This leads us to the view that consortia established just before a bidding deadline may not be robust enough to survive the rigors of forming agreement on the central issues of a multi-site study.

Also at the project initiation stage, while preparing the bid, it was invaluable to us that we could each contact our national representatives at the EU to seek information on the criteria which would be applied to our application, and then to share and pool this information. We learned in this way about the key criteria that we would need to satisfy to produce a bid more likely to succeed. We prepared the application over the period of a year, meeting several times, in the belief that study design options needed to be agreed face to face, so that we were all fully wedded to the final submitted bid, even though the meetings were at the expense of each study site at this preliminary stage.

To assemble the bid, the co-ordinating centre was agreed (London) and the bid was circulated and modified over many iterations. The application process for EU funding is unusually complex and time-consuming and required a whole series of forms for signature by PIs and by site administrative and financial officers, which again supported the need for long advance preparation time.

\section{PROJECT INITIATION}

Once we had received notification of the successful grant award, we met soon after to discuss what was necessary for the project start up. We learned a great deal from this phase. In fact it took us almost a year to decide exactly the final agreed form of the study protocol in all details. A lesson from this experience is that it is extremely important to 'freeze' the final protocol as early as possible, preferably before the start of the study, or at the latest in the first 3 months of the funding period, before any start on the main study. Associated with this, we came to a workable solution in terms of the structure of the study, for the co-ordination centre to delegate programmes of the study (referred to as 'work packages' by the EU) to centres, and to also transfer responsibility for these programmes to the named sites.
This stage was directly related to the question of the study budget. Several inter-related issues needed to be settled, in the context of a Concerted Action Programme, which pays for the co-ordination and concertation of a project, but not for the direct costs of the project itself. First, we needed to decide the balance between the costs awarded to the co-ordinating centre, for administration, data entry, data management, statistics, and for the travel and accommodation costs of co-ordination meetings. Second, we needed to decide how to allocate the grant between sites, given that the costs-of-living, and therefore the associated project costs, especially the costs of employing research staff, at each site varied between the five European sites (Denmark, England, Italy, Netherlands, and Spain). Third we needed to decide whether to allocate all the costs initially, or to withhold a contingency fund to manage unexpected cost pressures which arose during the course of the project. Again, these discussion lasted for many months, and we would recommend that the cost allocations between study centres, and to the study co-ordinating centres are fully agreed as early as possible, preferably at the grant application stage, to avoid unnecessary later delay as in our experience, sites were unwilling to commit to starting the main study until all the budgetary arrangements were agreed by all sites and were seen to be open and fair. At this initial stage we underestimated the complexity of such an international multi-site study.

\section{CONDUCT OF THE MAIN STUDY}

From our experience in the EPSILON study we learned that firm project management was essential. We set out a clear and agreed timetable for the tasks of each of the five study sites and for the work of the study co-ordinating centre. The Scientific Co-ordinator contacted each site on a regular basis to monitor progress to these specific targets, and notified all sites about all identified delays. Several times we needed to share information between sites to assist one site that had a particular difficulty. Two particular issues arose during the course of the main study that we, in retrospect, consider should have been finalised much earlier.

First, detailed negotiations were necessary over the study publications protocol. Because in all our countries publication record is used as a key criterion to judge academic merit and calibre, all sites wished to maximise their authorship outputs. At the same time, taking a longer term perspective, we wished to see the project succeed so that the collaboration would wish to bid together in future 
for further grants, by maintaining good personal and academic relations throughout the life of the study. We therefore discussed the publications protocol at each of our six monthly PI co-ordination meetings, and based our written publication agreement upon best practice, which was a publication outline prepared by Professor Sartorius, then at WHO. The agreement defined four blocks of papers, to be produced in sequence, which identified the main study papers, those describing the psychometric properties of the scales used in the study, papers concerned with the data results from the five sites, and a fourth category of further uni- or bi- or multi-lateral site papers which were allowable after the first three blocks were completed, to encourage papers with other collaborators, or with junior colleagues at our own sites. In addition to this, we agreed during the project the arrangements to produce a series of books containing the standardised scales which we are producing from our joint work.

Second, a vital stage of the study was to produce, edit and finalise the data template into which data from all the study sites would be entered. The templates were produced in SPSS, and each site needed to adapt the field names, where necessary, into the local language, although each item was given a unique alphanumeric identifier. In fact, associated with staffing changes at the coordinating centre, the final data template was not completed until the second half of the study, and this therefore required some adjustment of the previous data templates into which some data had already been entered, and so unnecessary time and complexity was introduced. We therefore recommend that the final data template also be 'frozen' at a very early stage of multi-site projects.

\section{PROJECT COMPLETION}

During the course of the study we were contracted by the EU to produce and deliver annual reports summarising the progress of the work, which acted as further stimulants to see that we were meeting our patient recruitment targets. The key step to supporting a successful series of publications from the study was to organise a writing-up week immediately after the end of the funding period. The PIs, along with one or two colleagues from each site, met with the co-ordinating centre scientific coordinator, data manager, statistician, statistical adviser, health economist and administrative officer for a week in a small hotel in southern England in mid-winter. Prior to this the final integrated data set was prepared, along with all data item identifiers, and the meeting rooms were prepared with enough computers to allow all staff to work in parallel for prolonged periods. Each day we met in plenary at the start and end of each day, and then worked in separate teams to draft the initial series of papers. We agreed to be constructively tough with each other in demanding a very high scientific standard of our written outputs from the study, and during our discussions many proposals emerged for further papers from the study. This was the most enjoyable and productive stage of the whole study, and produced first drafts of the eight papers which appeared in Thornicroft et al. (2000).

\section{CONCLUSION}

The EPSILON study has already led to the publication of over 20 data papers in peer-reviewed publications, along with a series of books in preparation which present the standardised study scales, and can reasonably be seen to be an example of successful European collaboration. The basis of this success is the set of trusting relationships between the Principal Investigators, so that the compromises intrinsic to such an international project were negotiated in ways accepted as reasonable, transparent and fair, along with ensuring that meetings were personally as well as scientifically rewarding. Our experiences suggest that such collaboration also allows more junior research staff to be involved so that they can gain invaluable experience of such large studies, and also learn about the mechanisms of EU grant applications, as a part of their own scientific career development. We have also learned that key elements of the study need to be brought forward in time to the very earliest stages of collaborative projects, especially freezing the study protocol, budgetary allocations, publications and authorship protocol, and the data entry template at the earliest possible occasion.

Acknowledgements. The following colleagues contributed to the EPSILON Study: Amsterdam, Dr. Maarten Koeter, Karin Meijer, Dr Marcel Monden, Professor Aart Schene, Madelon Sijsenaar, Bob van Wijngaarden. Copenhagen, Dr. Helle Charlotte Knudsen, Dr. Anni Larsen, Dr. Klaus Martiny, Dr. Carsten Schou, Dr. Birgitte Welcher. London: Professor Thomas Becker, Dr. Jennifer Beecham, Liz Brooks, Daniel Chisholm, Gwyn Griffiths, Julie Grove, Professor Martin Knapp, Dr. Morven Leese, Paul McCrone, Sarah Padfield, Professor Graham Thornicroft, Ian R White. Santander, Andres Arriaga Arrizabalaga, Sara Herrera Castanedo, Dr. Luis Gaite, Andrés Herran, Modesto Perez Retuerto, Professor José Luis Vázquez-Barquero, Elena Vázquez Bourgon. Verona, Dr. Francesco Amaddeo, Dr. Giulia Bisoffi, Dr. Doriana Cristofalo, Dr. Rosa Dall'Agnola, Dr. Antonio Lasalvia, Professor

Epidemiologia e Psichiatria Sociale, 11, 1, 2002 
Mirella Ruggeri, Professor Michele Tansella. This study was supported by the European Commission BIOMED 2 Programme (Contract BMH4-CT95-1151).

Thanks are due to Dr. J. Oliver for his permission to include the LQoLP in the EPSILON Study and for his helpful comments and assistance in its administration and scoring. We would also like to acknowledge the sustained and valuable assistance of the users, carers and the clinical staff of the services in the five study sites.

We would also like to acknowledge the sustained and valuable assistance of the users, carers and the clinical staff of the services in the five study sites.

In Amsterdam, the EPSILON study was partly supported by a grant from the Nationaal Fonds Geestelijke Volksgezondheid and a grant from the Netherlands Organization for Scientific Research (940-32007).

In Santander the Epsilon Study was partially supported by the Spanish Institute of Health -FIS- (FIS Exp. N $^{\circ}$ 97/1240).

In Verona additional funding for studying patterns of care and costs of a cohort of patients with schizophrenia were provided by the Regione del Veneto, Giunta Regionale, Ricerca Sanitaria Finalizzata, Venezia, Italia (Grant No 723/01/96 to Professor M. Tansella).

\section{REFERENCES}

Becker T., Knapp M., Knudsen H.C., Schene A., Tansella M., Thornicroft G. \& Vazquez-Barquero J.L. (1999). The EPSILON study of schizophrenia in five European countries. Design and methodology for standardising outcome measures and comparing patterns of care and service costs. British Journal of Psychiatry 175, 514-521.

Becker T., Knapp M., Knudsen H., Schene A., Tansella M., Thorni- croft G., Vazquez-Barquero J. \& the Epsilon Study Group (2000). Aims, outcome measures, study sites and patient sample: EPSILON Study 1. British Journal of Psychiatry 177, Suppl. 39, s1-7.

Chisholm D., Knapp M.R., Knudsen H.C., Amaddeo F., Gaite L. \& van Wijngaarden B. (2000). Client socio-demographic and service receipt inventory - European version: development of an instrument for international research. EPSILON study 5. European psychiatric services: inputs linked to outcome domains and needs. British Journal of Psychiatry, Suppl. 39, s28-33.

Gaite L., Vazquez-Barquero J., Arrizabalaga A., Schene A., Welcher B., Thornicroft G., Ruggeri M., Vazquez-Bourgon E., Retuerto Perez M., Leese M. \& the Epsilon Study Group (2000). Quality of life in schizophrenia: development, reliability and internal consistency of the Lancashire Quality of Life Profile-EU Version. Epilson Study 8. British Journal of Psychiatry 176, Suppl. 39, s49-54.

Knudsen H., Vazquez-Barquero J. Welcher B., Gaite L., Becker T., Chisholm D., Ruggeri M., Schene A., Thornicroft G. \& the Epsilon Study Group (2000). Translation and cross-cultural adaptation of outcome measurements for schizophrenia: EPSILON Study 2. European Psychiatric Services: Inputs Linked to Outcome Domains and Needs. British Journal of Psychiatry, 176, Suppl. 39, s8-14.

McCrone P., Leese M., Thornicroft G., Schene A., Knudsen H., Vazquez-Barquero J. Lasalvia A., Padfield S., White I., Griffiths G. \& the Epsilon Study Group (2000). Reliability of the Camberwell Assessment of Need--European Version. EPSILON Study 6. European Psychiatric Services: Inputs Linked to Outcome Domains and Needs. British Journal of Psychiatry, Suppl. 39, s34-40.

Thornicroft G., Becker T., Knapp M., Knudsen H.C., Schene A., Tansella M. \& Vazquez-Barquero J.L. (2000). Reliable outcome measures for mental health services research in five European countries: the EPSILON study. British Journal of Psychiatry 177, Suppl. 39. 